\title{
CONCEPTUAL FRAMEWORK OF BLENDED PROFESSIONAL DEVELOPMENT FOR MATHEMATICS TEACHERS
}

\author{
Hea-Jin Lee \\ Ohio State University-Lima
}

\begin{abstract}
The study presents a conceptual framework of a blended professional development program for teacher success in learning a subject matter and enhancing instructional practice. Twenty-nine middle school teachers (22 first-year and 7 continuing teachers) participated in a year-long, blended professional development (PD) program. Effects of the blended PD program were measured by analyzing the content of participants' virtual interactions; i.e., 1,149 online threaded discussion messages. The continuing teachers were more actively engaged in the online community of practice than the first-year teachers. The types of structured assignments and learning time influenced the level of participation but did not make a significant impact on the interaction content. Most virtual interactions involved sharing instructional ideas based on personal experiences. Results showed participants' teaching practices changed toward more student-centered lessons, encouraging verbal engagement, using various questioning strategies, and using collaborative group work while employing a wider variety of resources.
\end{abstract}

\section{KEYWORDS}

Blended professional development, mathematics teacher education, content of virtual interactions

\section{INTRODUCTION}

There are an increasing number of online and blended professional development programs [1]. However, considering the growing number, the effectiveness of the professional development (PD) program, including systemic aids, PD tasks, and evaluation strategies, remain vague. This study aims to understand how to best support teachers learning through an online system in a blended PD program. This study is based on a year-long professional development program for middle school mathematics teachers. The purpose of the program was to maximize teacher learning in mathematics, improve instructional practice, and foster productive professional interactions among mathematics teachers. This paper was guided by the research question: how do blended professional learning opportunities impact the professional development of mathematics teachers?

\section{CONCEPTUAL FRAMEWORK}

The features of an effective blended professional development program can be designed to facilitate professional development for teachers. The PD program investigated provided a blended learning option that has the potential to increase sense of community [2] and professional learning. 
Figure 1 depicts a conceptual framework for a professional development program involving contextualized practice and active construction of knowledge.

Since Dewey, the social nature of all human learning and the role of communication skills and abilities in

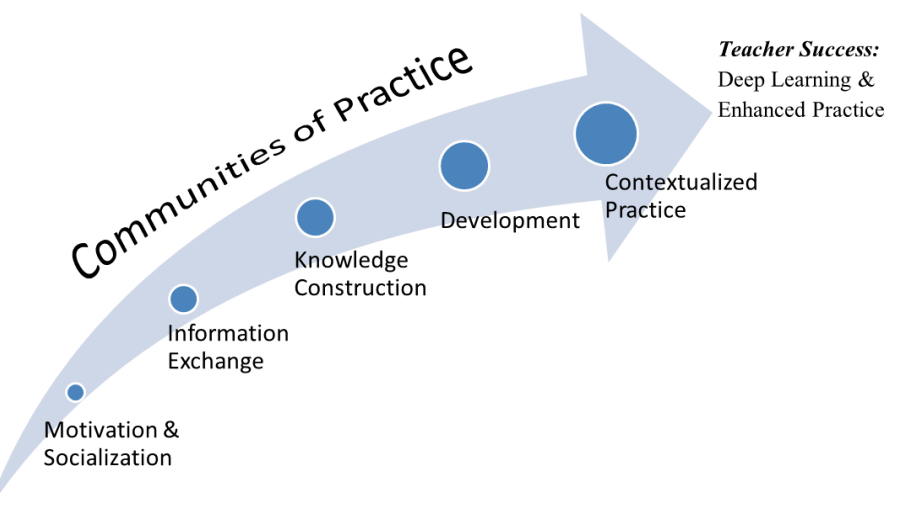

Figure 1. Conceptual Framework of the Professional Development Program

the human development process are the most often discussed concepts in higher education [3, 4]. Learning in communities of practice relies on successful communication between individuals, and learning occurs as interaction among practitioners takes place $[4,5]$. As far as communities of practice are concerned, "there is no one on the stage who is the knowledge source, but all individuals have an equal right to share their experience, and their stories are valuable contributions to the community" [4, para. 3].

It was recognized that a sense of community was critical for sustaining teachers' interests and that faceto-face meetings were vital in expanding and supporting professional learning communities. Participants in the program came from various backgrounds and diverse experiences, which made bonding a challenge. The assumption was that if teachers could form a community in supporting and learning from each other, then they would be more likely to succeed with their learning.

Salmon [6] presents a five-stage model for online courses with roles for participants and instructor:

1. Access and Motivation

2. Socialization

3. Information Exchange

4. Knowledge Construction

5. Development

Salmon's model served as a basis for designing a blended PD program for this study, for selecting the PD topics, and for organizing the sequence of the PD topics. While Salmon's model was designed for 100\% online courses and general populations, the conceptual framework of this study is for a blended PD program for practicing teachers, and the five-stage model was modified:

1. Motivation and Socialization

2. Information Exchange

3. Knowledge Construction

4. Development

5. Contextualized Practice

In a blended PD program, the Motivation and Socialization stage can be approached either face-to-face or virtually. If face-to-face contact is utilized, the first stage can be accomplished in a shorter amount of time but is as equally effective as virtual contact. During this stage, participants should gain information about the PD program/courses, get familiar with the PD system, learn the technology to be used for the online 
sessions, begin to establish a network with other participants and instructors, and become motivated to participate in the PD. Deep understanding or implementation of learning is not expected in the Motivation and Socialization stage. Instead, the PD instructors present course guidelines in the Information Exchange stage and personalize course activities while encouraging participants to exchange.

In the Knowledge Construction and Development stages, participants collaborate to establish common understanding of mathematical concepts and instructional strategies taught in the PD and reflect on their learning. Rovai [7] found a "positive significant relationship between a sense of community and cognitive learning" (p. 328). Mere interaction among participants, however, does not guarantee meaningful cognitive engagement or facilitate meaningful learning and understanding. According to Walker and Chappell [8], when we discuss student learning, our question should not be whether students can or cannot achieve mathematical skills but whether students will realize maximum success in mathematics. This view suggests an instructional approach that encourages students to communicate, problem solve, and engage in learning mathematics conceptually $[9,10]$ and should guide PD program activities. The participating teachers in this study were expected to "build knowledge through inquiry-based collaborative interaction with other teachers and become co-learners and act as facilitators" [11, p.4].

Professional development programs should provide opportunities for participating teachers to "learn mathematics around specific content and teaching situations that may arise in practice" [9, p. 56], as well as provide opportunities for teachers to implement/practice their learning in their own classrooms, which is called the Contextualized Practice stage in the study. The key concerns, therefore, are ensuring peer exchange of ideas and information; the creation and assimilation of knowledge [12]; and providing a climate of accelerated change in which participants access up-to-date knowledge and apply new skills in changing circumstances [13]. The community of practice should not simply be a forum for the exchange of information but should progress in response to the diverse needs of learners and the communities in which they work [14].

\section{PROFESSIONAL DEVELOPMENT PROGRAM OF THE STUDY}

The professional development program of this study, Teaching Algebra in Context, Community, and Connections (TACCC), was designed to improve student mathematics knowledge and attitude by (1) increasing teacher content knowledge and (2) improving instructional skills to teach mathematics concepts in an environment rich in context, community, and connections. Figure 2 depicts the blended PD program of the study.

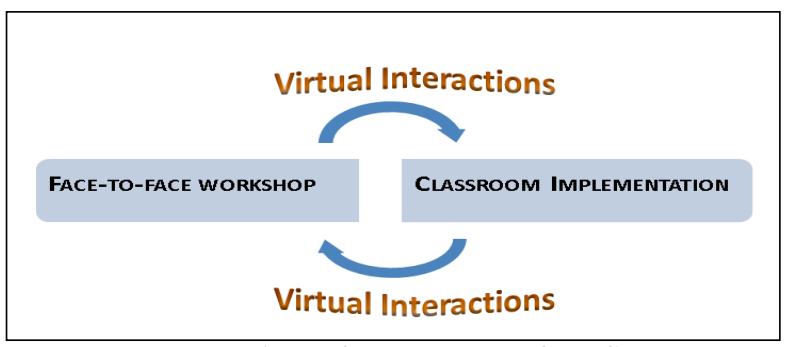

Figure 2. PD Model of the Study

The major activities of the project consisted of three components: face-to-face workshop courses, webbased learning sessions through virtual interactions, and classroom implementation.

As Blank, de las Alas, and Smith [15] also reported, the PD developers also believe that high quality, inservice PD should include content focus, active learning by teachers, collective participation, coherence with curriculum/standards, and sufficient time. The assumption was that if teachers could form a community in supporting and learning from each other, then they would be more likely to succeed with their professional learning. 


\section{A. Face-to-face Workshops}

The PD program of the study was a year-long program with three graduate-level workshop courses. Faceto-face meetings were held once a month over nine months. There were groups of 2-4 teachers from the same school district with a total of 29 participants. This number of participants provided teachers with opportunities to develop a support system and work collaboratively, even while their different backgrounds and diverse experiences made bonding a challenge. In order to facilitate the active learning of these teachers, face-to-face workshops were conducted through discussions, collaborative group work, hands-on activities, problem-solving opportunities, and presentations by participants. Project assignments included discussions of readings, reflection on workshop activities, solving mathematical problems using invented methods, and developing mathematical tasks and analyzing their solutions.

\section{B. Web-based Learning through Virtual Interactions}

Virtual interactions occurred between monthly face-to-face meetings using Desire2Learn. Asynchronous communication tools (e-mail and threaded discussion boards) were used not only to allow participants to contribute at their convenience, but also to give them time to implement and reflect on their learning and practice. The objective of online activities in the TACCC blending learning system was not to replace face-to-face instruction but to enhance the face-to-face learning experience. That is, the online activities/assignments aligned with the face-to-face workshop agenda and were scheduled to align with overall TACCC PD objectives.

Participants had the opportunity to experience the first two stages of the modified Salmon model [6] (Motivation and Socialization as well as Information Exchange) before participating in online activities during the first face-to-face meeting and communicating via e-mail. Regarding the online activities, assignment 1 consisted of reading reflection and discussion and assignment 2 focused on discussion of videotaped best practices. Assignments 1 and 2 focused on the Knowledge Construction stage; assignments 3, 4, and 5 (implementing a discovery-based lesson) targeted the Development and Contextualized Practice stages.

The five structured online assignments were given during the academic months. Teachers were required to post an initial message responding to the prompt for each online assignment. In addition, they were expected to participate in threaded discussions, providing comments on other teachers' messages - at least five per assignment. During the summer, they participated in face-to-face meetings for one week, and no online activities were given at that time.

\section{Classroom Implementation}

To make a difference in classrooms, PD programs must build in time for teachers to implement new practices between PD meetings either face-to-face or virtual. Effective practice is developed best through ongoing support of teachers in real classroom settings. Between monthly face-to-face workshop meetings in the study, participants were expected to implement ideas learned from the TACCC PD in their own classrooms. They were also encouraged to share ideas from the program with other teachers in their buildings and districts. In addition, a project instructor visited each participant's classroom and observed their teaching or co-taught one or two lessons with the participant. Each face-to-face meeting started by discussing and sharing the outcomes of the newly implemented instructional methods and student responses/learning. Participating teachers were also required to share their lesson plans and reflections with the rest of the PD participants during the online portion of the program.

\section{METHODOLOGY}

Measuring the effectiveness of professional development for mathematics teachers has been undertaken with various foci. As discussed earlier in the conceptual framework section, teacher success can be achieved through continuous effort in constructing knowledge and implementing practice under the support of communities of practice. For the purpose of this study, the focus was on the teachers' 
construction of knowledge and learning processes, as observed in virtual interactions in the online community of practice.

\section{A. Data Collection}

Twenty-nine middle school teachers participated in TACCC. Twenty-two teachers were new TACCC participants, and seven teachers had participated in an earlier TACCC PD program. The TACCC PD courses were offered in three quarters. Since the first quarter was devoted to refreshing teachers' understanding of algebra concepts and to exploring the use of algebraic concepts across the grade levels in middle school, the study organizers assumed that the seven returning teachers received this instruction from their previous PD sessions. Therefore, the seven returning teachers joined the PD program in the summer quarter, after the first year teachers completed the first course. The second and third courses focused on both understanding of algebra concepts and teaching algebra in context, community, and connections.

Between face-to-face workshop meetings, teachers posted messages in response to a given discussion prompt and communicated with each other using asynchronous online discussion posting. Assigned prompts/topics and total numbers of posted messages are summarized in table 1.

\begin{tabular}{|l|l|l|l|}
\hline Assignment & Topic & Purpose & $\begin{array}{l}\text { Total no. of } \\
\text { messages }\end{array}$ \\
\hline 1 & Reading reflection and discussion & Knowledge Construction & 237 \\
\hline 2 & $\begin{array}{l}\text { Discussion on videotaped best practice } \\
\text { lessons }\end{array}$ & Knowledge Construction & 204 \\
\hline 3 & Implementing a discovery-based lesson & $\begin{array}{l}\text { Development \& } \\
\text { Contextualized Practice }\end{array}$ & 166 \\
\hline 4 & Implementing a discovery-based lesson & $\begin{array}{l}\text { Development \& } \\
\text { Contextualized Practice }\end{array}$ & 260 \\
\hline 5 & Implementing a discovery-based lesson & $\begin{array}{l}\text { Development \& } \\
\text { Contextualized Practice }\end{array}$ & 282 \\
\hline
\end{tabular}

Table 1. Virtual Interaction Data

\section{B. Data Analysis}

The discussion threads in each topic were used as the unit of data collection and analysis. All of the postings (1,149 messages) among the 29 participants were analyzed and coded using the criteria described in figure 3 . Three coders were trained and checked for inter-rater reliability at the end of training by using a sample set. Assignment 1 postings ( 237 messages) were coded by all three coders and checked for interrater reliability. For assignments 2, 3, 4, and 5, each coder was assigned a series of threads to code. The coders and researcher had regular meetings to discuss issues and questions. Figure 3 depicts the subcategories of each variable and the data analysis structure. 


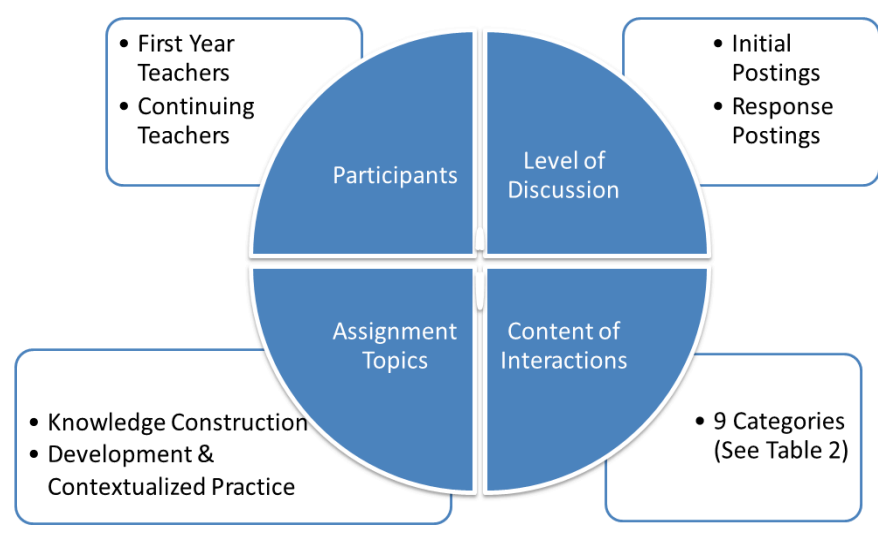

Figure 3. Data Analysis Structure

The content analysis codes were founded on Gareis and Nussbaum-Beach [16], Interstate New Teacher Assessment and Support Consortium [17], and the Joint Committee on Standards for Educational Evaluation [18]. The codes were finalized after two initial analyses. Gareis and Nussbaum-Beach [16] used six categories: Acknowledgement, Guided Advice, Sharing Experience, Specific Questions/Seeking Specific Information, Explicit Issue/Problem, and Reflection/Professional Growth. In addition to these six categories, TACCC added three content analysis codes: simple agreement, instructional ideas, and students. In order to examine the influence of the PD course materials, the instructional ideas code was added to differentiate from the Sharing Experiences category. The students code was added because TACCC participants were classroom teachers, and issues/problems related to students also received attention from project participants. Table 2 provides sample messages for each code.

\begin{tabular}{|l|l|}
\hline Codes & Sample messages \\
\hline Reflection & $\begin{array}{l}\text { "I should be more forth coming making sure they hold the spaghetti towards the end } \\
\text { of the spaghetti and maybe they would have achieved better results." }\end{array}$ \\
\hline $\begin{array}{l}\text { Sharing } \\
\text { Experience }\end{array}$ & $\begin{array}{l}\text { "I did this activity with my Algebra class. I found this lesson through the Math } \\
\text { Portal site. The lesson took two class periods, which are about 42 minutes in } \\
\text { length." } \\
\text { " } \ldots \text { but I always have a few kids who just write one or two words..." }\end{array}$ \\
\hline $\begin{array}{l}\text { Question/ } \\
\text { Suggestion }\end{array}$ & $\begin{array}{l}\text { "With all of the variables that prevented a linear graph, was it worth it or would you } \\
\text { use a different route?" }\end{array}$ \\
\hline Instructional Ideas & $\begin{array}{l}\text { "Geometry Made Simple (High School Edition), Frank Schaffer Publications-This } \\
\text { is where I found the Logic 101 questions. www.printable-puzzles.com-This is } \\
\text { where I found the logic puzzle. This is a great website with a lot of different types } \\
\text { of puzzles (crosswords, sudoku, cryptograms, word searches, etc.)." }\end{array}$ \\
\hline Students & $\begin{array}{l}\text { "They always want to help so and so add to their answer-no one ever tells another } \\
\text { student, 'No, you're wrong."” }\end{array}$ \\
\hline Guided Advice & $\begin{array}{l}\text { "I covered my box with metallic Contact paper, which by the way is dry erase. I } \\
\text { then used a piece of sparkle craft foam for the screen and white craft foam for the } \\
\text { dial. Lastly, I used a pair of old school (large) headphones for the top. Easy and } \\
\text { durable!" }\end{array}$ \\
\hline Simple Agreement & "I agree that the number line is a great way to get the year started." \\
\hline Acknowledgement & "I am interested in seeing this in action. It does sound like a good activity." \\
\hline
\end{tabular}


Table 2. Sample Messages

\section{RESULTS}

This study investigated the learning process of middle school mathematics teachers by measuring their knowledge construction and learning implementation within their own classrooms and by analyzing project participants' virtual interactions. The findings were summarized in three sections: the level of participation in relation to the other variables, the content of interactions, and the relationship between discussion content and associated assignment topics.

\section{A. Level of Participation}

Figure 4 compares the level of participation in each assignment by calculating the average number of messages posted per assignment. The first-year teachers were more engaged in the Knowledge Construction stage assignments (assignments 1 and 2) than the Development and Contextualized Practice stage assignments (assignments 3, 4, and 5). Assignments 3, 4, and 5 required creation and implementation of discovery-based lessons as well as critique of peer teachers' work. The study could not directly compare first-year teachers' engagement to the engagement of continuing teachers for the first three assignments because the continuing teachers only joined the program in the summer after the first set of online assignments had been completed.

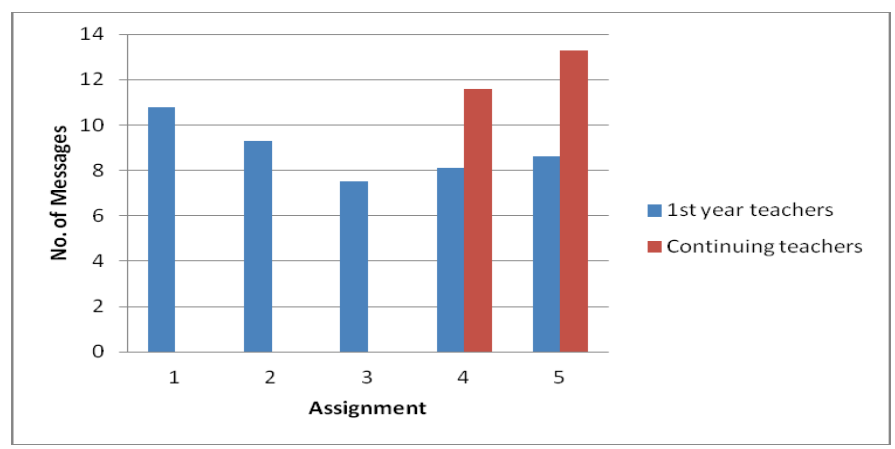

Figure 4. Average No. of Messages per Assignment

For assignments 4 and 5, the level of engagement was much higher for the continuing teachers; they interacted with an average of 12.4 messages per assignment, while the first-year teachers posted an average of 8.9 messages per assignment. Every continuing teacher posted more than 8 messages for each assignment, while approximately 10 of the 22 first-year teachers posted more than 8 messages per assignment. Both groups exceeded the minimum requirement of five messages per assignment.

The TACCC project team expected more frequent and active participation in the Development and Practice stage for assignments 3, 4, and 5 because teachers should have built a certain level of an online community of practice by then. In addition, since assignments 3, 4, and 5 were learner controlled activities, the project team anticipated internally motivated participants with more ideas to share in the Development and Practice assignments than in the Knowledge Construction assignments. However, the first-year teachers participated less in the Development and Practice assignments than they did in the first two assignments. However, a positive finding was that the first-year teachers increased their level of engagement specifically in the Development and Practice assignments from 7.5 to 8.1 messages per teacher in assignments 3 and 4 respectively before reaching 8.6 messages per teacher in assignments 5 . The continuing teachers' participation was much higher than the first-year teachers in the Development and Practice assignments, possibly due to their comfort level with the web-based learning support system and their greater appreciation of virtual communication with other professionals. 


\section{B. Content of Interactions}

Several common concerns and topics appeared in participants' virtual interactions, regardless of the intended purpose of the assignments or the level of discussion, both in initial and response postings. Figure 5 summarizes the frequency of topics that occurred in participants' interactions.

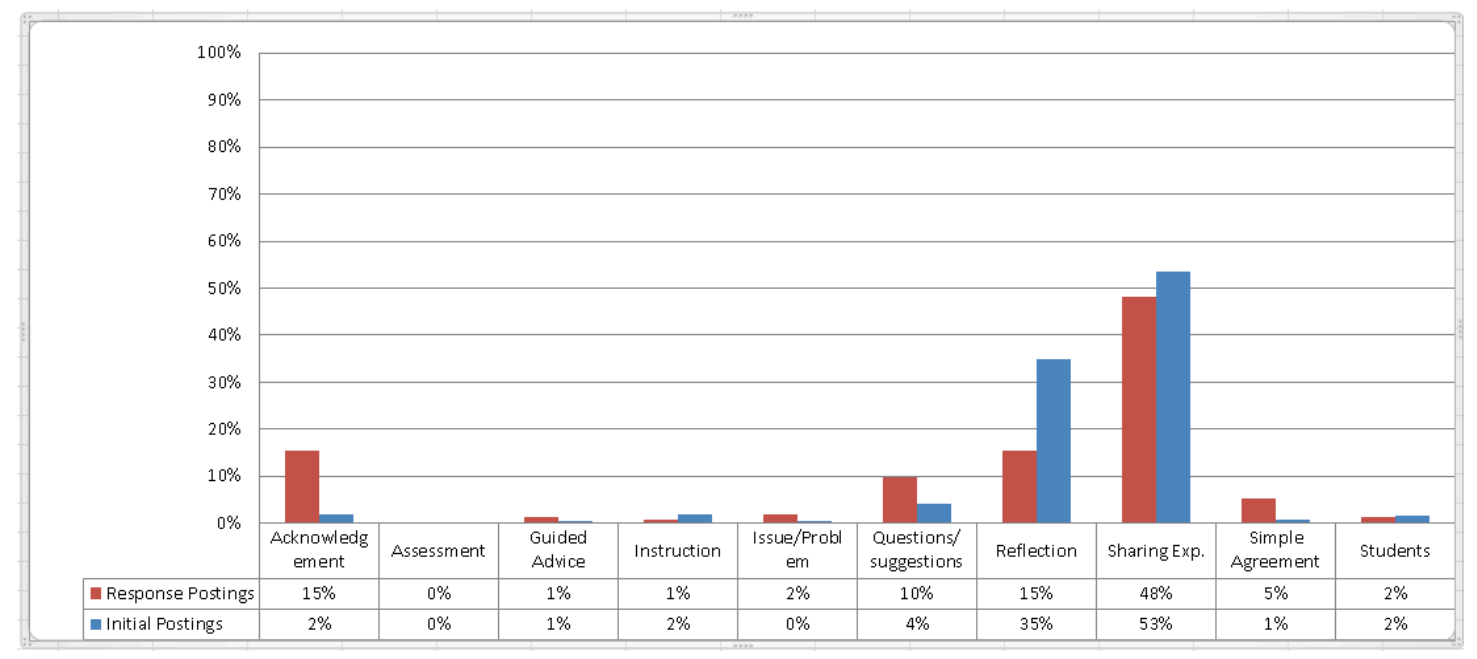

Figure 5. Content of Interactions

More than $50 \%$ of participants' initial messages were devoted to sharing their experiences, and $35 \%$ of messages maintained the topic of the initial postings. Sharing experiences remained the most popular response topic (50\%) followed by acknowledgement and reflection, and questions/suggestions. Teachers' virtual interactions (online postings) were mostly focused on how to work with certain math concepts, sharing their personal experiences, and asking questions concerning instructional delivery. Specifically, most discussions touched on how to relate math concepts to the real world; how well a specific instructional strategy works; games and websites that could help their students with learning concepts; creative ways to demonstrate concepts to their students; the most effective way to use manipulatives in the classroom; how to allow for more student-centered time in the classroom; the concept of mistakes in math and how they may be turned into mini-lessons; connections between different concepts covered and standards that needed to be addressed; the use of vocabulary as a way to help with math communication; and how to overcome time constraints to allow participants to teach the "why" of math as much as they would like to. Most of these topics were face-to-face workshop agenda items and project goals.

Teachers also shared struggles they personally faced with math and how they have used those experiences to help their students. Participants discussed personal connections from their own learning in school and also things they still want to learn in order to ensure students have better experiences than they did. They also discussed the common fear of not knowing how to explain the "why" of math concepts to students, which was the most important disposition advocated by the TACCC program. Participating in a professional development program seemed to help these teachers better understand students' feelings and dispositions.

There was also a great deal of discussion about how important it is for a teacher to be able to continue to learn and make changes in the classroom in small increments to make it both easier and more feasible. Participants started to value a community of practice even more after participating in virtual interactions with other teachers. They expressed how important it is to find time to talk to and work with colleagues. 


\section{Relationship between the Content of Interactions and Assignment Topics per Discussion Level}

Figures $6 \mathrm{a}$ and $6 \mathrm{~b}$ show the relationship between the content of interactions and the assignment topics within the level of discussions for both initial and response postings. Reading Reflection (assignment 1) and Video Critique (assignment 2) were tasks to support teacher construction of knowledge. The Discovery-Based Lesson Plan (LP) (assignments 3, 4, and 5) aimed to enhance teachers' classroom practice.

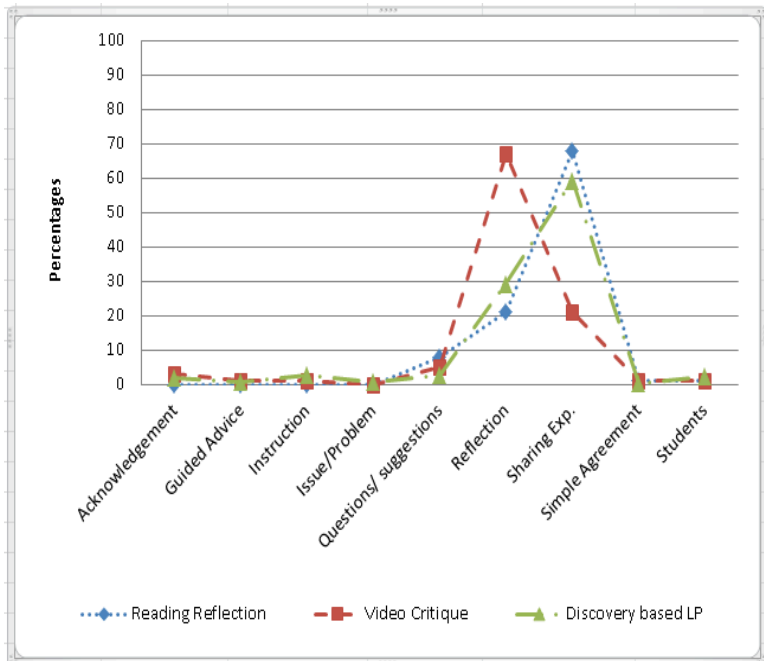

a. Initial Postings

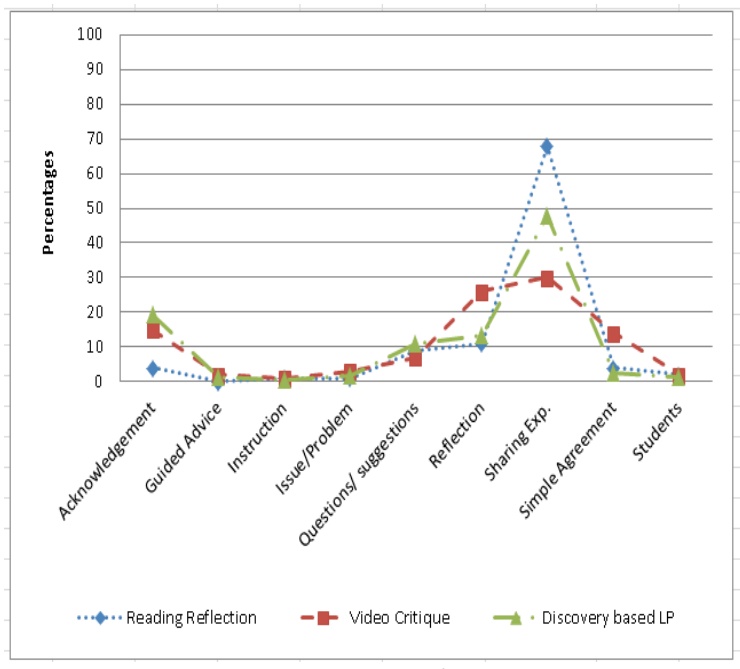

b. Response Postings

Figure 6. Content Comparison within the Level of Discussions by Project Focus

An average of $25 \%$ of teacher interactions consisted of Reflection and $51 \%$ consisted of Sharing Experience. Other content areas each made up less than 10\% of the total interactions: $9 \%$ Acknowledgement, 7\% Questions/Suggestions, 3\% Simple Agreement, 2\% Student Related Issues, and $1 \%$ of Guided Advice.

The Reading Reflection assignment, assignment 1 did not trigger different discussion foci between initial and response interactions. Sixty-eight percent of interactions were about sharing personal experiences even though teachers were supposed to discuss the reading material and reflect on their practice as compared to the recommended practice. The project team anticipated more interactions would be classified as Reflection and Instruction than other discussion content categories The discussion in response to the Reading Reflection assignment included issues of time constraints; the need to re-teach concepts; knowing how to explain the "why" of concepts; use of math vocabulary; the problem of teaching differently than the way the teacher originally learned concepts; ways to assist colleagues with engaging students in lessons; teaching specific concepts, such as graphing, equations, and the most effective way to use manipulatives; the importance of relating math concepts to real-world experiences; collaborating with other educators; using games, websites, and hands-on activities to teach concepts; and recognizing that all teachers across subject areas can and do struggle with similar issues in the classroom.

Assignment 2 involved watching either a 7th or 8th grade algebra class and critiquing the lessonfocusing on the teacher's practice and students' interactions/engagement. In the online environment, the two main areas of focus in initial postings in this assignment were Reflection $(67 \%)$ and Sharing Experience (21\%); participants continued to interact primarily in the areas of Sharing Experience (30\%) and Reflection (26\%) in follow-up responses in the discussion thread. Even through participants were supposed to criticize and provide feedback about another teacher's instruction, their main focus was not instruction but sharing their own experience and reflecting on their own instruction. These findings do not 
imply a negative outcome for the project or that the professional learning was not met but shows that certain PD assignments do not serve the intended goal/objective.

There was a difference in the content of initial messages among assignments 3, 4, and 5. Figures $7 \mathrm{a}$ and $7 \mathrm{~b}$ depict the assignments separately. Assignments 3, 4, and 5 involved the development of a discoverybased lesson plan, implementation of the lesson, reflection on the lesson, and commenting on peer teachers' lesson plans. Figures $6 \mathrm{a}$ and $6 \mathrm{~b}$ show the combined data of assignments 3,4 , and 5 , three discovery-based lesson implementations, the purpose being development and contextualized practice. The majority of both initial and response discussion postings were Sharing Experience $(60 \%$ of initial posts and $48 \%$ of responses). If we only look at initial interactions, approximately $30 \%$ of messages were classified as Reflection.

Sixty-seven percent of discussion posts were classified as Reflection after assignment 3, while teachers spent more time in sharing experiences (over $80 \%$ ) after teaching their second and third discovery-based lessons (figure $7 \mathrm{a}$ ). On the other hand, $24 \%$ of response postings were Reflection and $24 \%$ of response postings were Sharing Experiences following the first discovery-based lesson, while $60 \%$ of messages were Sharing Experiences for both the second and third lessons (figure 7b).

It is not clear why messages related to the second and third discovery-based lessons were different from the messages for the first one. Possibly, the teachers followed a standardized development process for the first lesson, which ends with reflection. However, for the second and third discovery-based assignments, project participants did not reflect on their lesson as much but shared their ideas and experiences instead. Teachers shared ideas about how to include more student-led lessons and ways to more easily teach mathematics with the use of relevant connections. One of the teachers mentioned in a discussion post that "it is okay to jump around and cover things in your own way as long as your students are learning. You don't have to follow a specific set of guidelines in one set order to accomplish what is needed." This message reflects that instructors modeled the face-to-face workshop sessions and that the program motivated more discussions about resources and ideas to make math lessons more interactive and interesting.

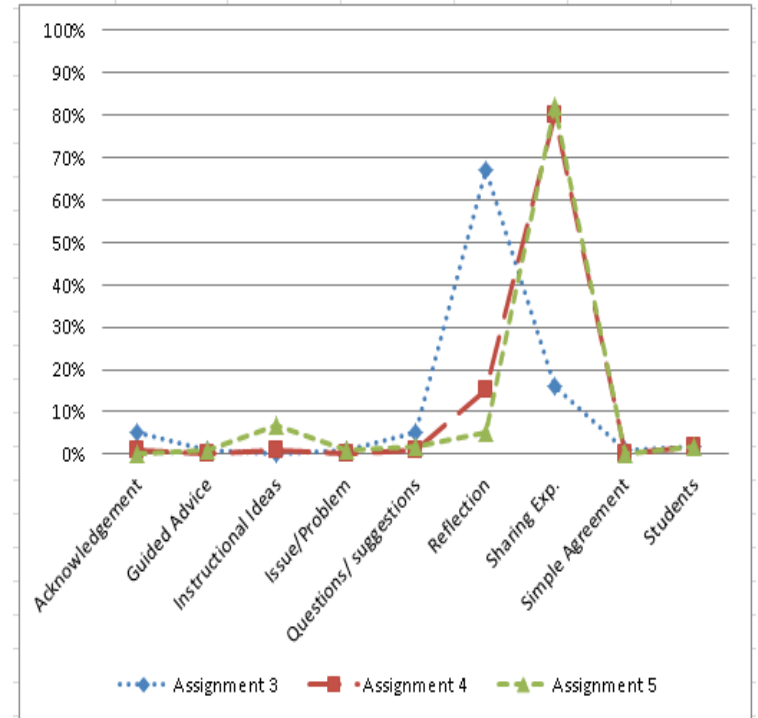

a. Initial Postings

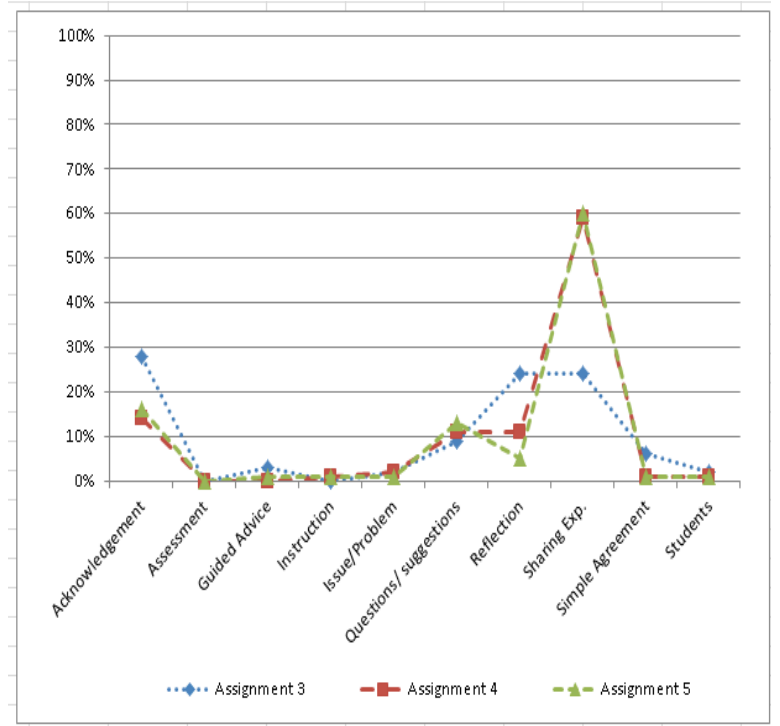

b. Response Postings

Figure 7. Content Comparison for Discovery-based Lesson Plan Assignments

\section{CONCLUSIONS}

This study investigated the effectiveness of a blended professional development program by examining 
the nature of participants' learning processes in knowledge construction and classroom practice through virtual interactions. Regarding the effectiveness of the virtual interactions, there were some trivial findings and unexpected outcomes that can provide insight for mathematics educators. Most face-to-face discussions centered on the activity or mathematics problems that were presented in class, whereas online discussions focused on reflection and shared experiences from the participants' classrooms. The study suggests that the use of online learning combined with face-to-face meetings is very beneficial. Teachers were able to share actual classroom experience and get feedback from other professionals or share new ideas and available resource possibilities. The teachers in this study had very productive conversations via online discussion postings, in which they were talking about specific classroom events and asking questions to get more information about mathematics and teaching mathematics. These queries were in turn given well-developed responses.

The content of online discussions did not vary significantly between the different assignment types and the project focus. Even though TACCC assignments were designed to address Knowledge Construction, Development, and Contextualized Practice, the main focus of virtual interactions was, in all cases, the sharing of personal experiences rather than addressing material learned from the readings and classroom observations. It is important to investigate how different online discussion topics contribute to the teachers' active participation and the content of interactions.

However, the content of interactions does not measure the depth of learning. That is, analyzing the content of interactions (the actual learning process) can lead to the assessment of objective achievement in online assignments (expected learning) but cannot measure the depth of learning: surface learning versus deep learning. Ways to connect the purpose and content of interactions with the depth of learning are needed as a follow-up to the content analysis study.

Another interesting finding was the difference in the level of participation. First-year teachers contributed more to Knowledge Construction assignments, in which they were asked to reflect on book readings or videotaped best practices, than for the Development and Practice assignments, which required developing and implementing a discovery-based lesson. What teacher educators can learn from this finding is the sequential order of the online professional development program as described in the conceptual framework of the study: gaining knowledge, deepening understanding, and implementing learning. Regarding blended PD programs, this study determined that practitioners need plenty of time to familiarize themselves with the technology. That is, additional structured activities need to be provided for in-service teachers to fully utilize Salmon's [6] first two stages: (1) Access and Motivation and (2) Socialization. Teacher educators should also consider the importance of investigating how different online discussion topics and assignments contribute to their active learning and participation. Professional development programs for mathematics teachers deal with different topics than regular college level (mathematics) courses. Therefore, assignments for knowledge construction and development should aim at linking theory and practice and reflect participants' teaching contexts, their level of subject familiarity, and the needs of the individual teacher/school. Teacher educators should also investigate the different social media tools that other teachers use in the classroom. The level of participation, learning process, and outcomes may be influenced by the types of tasks, project focus, the mode of communication (verbal vs. written), and the type of systemic tools.

\section{ABOUT THE AUTHORS}

Rana Khan is a professor and Chair of the Information and Technology Systems department at the University of Maryland University College. She is also the director of Professional Science Master's program in Biotechnology. She has published articles on integrating industry-sponsored projects in online capstone courses and designing and implementing an E-mentoring program for online graduate students. Prior to her work in online education, she was a research scientist. She holds a Ph.D. in Cell and Molecular Biology from the University of Maryland at College Park. 


\section{REFERENCES}

1. Borba, M.D.C., and Llinares, S. Online Mathematics Teacher Education: Overview of an Emergent Field of Research. ZDM Mathematics Education, 44, 697-704 (2012). DOI 10.1007/s11858-012-0457-3.

2. Rovai, A.P., and Jordan, H.M. Blended Learning and Sense of Community: A Comparative Analysis with Traditional and Fully Online Graduate Courses. International Review of Research in Open and Distance Learning (August 2004).

3. Feldman, D.H. Forward. In: John-Steiner, V., Creative Collaboration Oxford University Press: New York, ix-xiii, 2000.

4. Heinze, A., and Procter, C. Communication - a Challenge and an Enabler for Facilitating Blended Learning Community (2005). http://orgs.man.ac.uk/projects/include/experiment/heinze_proctor.pdf.

5. Kahan, S. Etienne Wenger on Communities of Practice: Engagement, Identity \& Innovation. The Journal of Association Leadership (March 2004).

6. Salmon, G. E-Moderating: The Key to Teaching and Learning Online. Kogan Page: London, 2000.

7. Rovai, A.P. Sense of Community, Perceived Cognitive Learning, and Persistence in Asynchronous Learning Networks. Internet \& Higher Education, 5(4): 319-332 (2002).

8. Walker, P.C., and Chappell, M.F. Reshaping Perspectives on Teaching Mathematics in Diverse Urban Schools. In Trentacosta, J. (Ed.), Multicultural and Gender Equity in the Mathematics Classroom: The Gift of Diversity, National Council of Teachers of Mathematics: Reston, VA, 201208, 1997 Yearbook.

9. Brown N., and Benkenp, B. So When Do We Teach Mathematics? Vital Elements of Professional Development for High School Mathematics Teachers in an Urban Context. Teacher Education Quarterly, 55-73 (Summer 2009).

10. National Council of Teachers of Mathematics. Principles and Standards for School Mathematics. Author: Reston, VA, 2000.

11. U.S. Department of Education (USDE), Office of Planning, Evaluation, and Policy Development. Evaluation of Evidence-based Practices in Online Learning: A Meta-analysis and Review of Online Learning Studies, USDE: Washington, D.C., 2010.

12. Thomas, G. Knowledge as an Asset-a View from Industry, Journal of Computer Assisted Learning, 8: 131-152 (1992).

13. Hargreaves, A. Changing Teachers, Changing Times. Cassell: London, 1994.

14. Chapman, C., and Ramondt, L. (Eds.). Online Communities-Final Report: Developments in the Communities of Practice and the Programme Communities. Report to the National College of School Leadership, September 2002-October 2003.

15. Blank, R.K., de las Alas, N., and Smith, C. Analysis of the Quality of Professional Development Programs for Mathematics and Science Teachers: Findings from a Cross-State Study, Council of Chief State School Officers: Washington, DC, 2008. http://programs.ccsso.org/content/pdfs/Year_2_IMPDE_Fall_06_Rpt_with_errata-041708.pdf.

16. Gareis, C.R., and Nussbaum-Beach, S. Electronically Mentoring to Develop Accomplished Professional Teachers. Journal of Personal Evaluation in the Education Website, 20: 227-246 (2007).

17. Interstate New Teacher Assessment and Support Consortium (InTASC). Model Standards for Beginning Teacher Licensing and Development: A Resource for State Dialogue, InTASC: Washington, DC, 1992.

18. Joint Committee on Standards for Educational Evaluation. The Personnel Evaluation Standards, Corwin: Newbury Park, CA, 1988. 